to 20 cigarettes a day) in September, 1951. In another instance, the doctor had described himself as smoking $3 \frac{1}{2} \mathrm{oz}$. of pipe tobacco a week, but a friend, who signed the death certificate and had known him for 25 years, stated he had previously been one of the heaviest smokers of both cigarrettes and pipe he had ever known. Such factors not only could not produce an exaggeration of the true relationship but must lead to an understatement of it by inflating the mortality among light smokers and reducing the mortality among heavy smokers.

The investigation has not, as yet, continued long enough to show whether there is a relationship between smoking and the mortality from any other disease, but from the preliminary figures it would seem unlikely that there is any as close as that observed with lung cancer. The numbers of deaths, however, from some potentially interesting diseases are as yet small (for example, from cancer of the buccal cavity and larynx and from duodenal ulcer). There have, on the other hand, been a large number of deaths attributable to coronary thrombosis. It seems clear that smoking cannot be a major factor in their production, but the steady increase in mortality with the amount of tobacco smoking recorded suggests that there is a subgroup of these cases in which tobacco has a significant adjuvant effect.

\section{Summary}

At the end of 1951 some 40,000 men and women on the British Medical Register replied to a simple questionary relating to their smoking habits. On that basis they were divided into non-smokers and three groups of smokers (including ex-smokers) according to the amount they smoked at that time (or when they gave up).

The certified causes of death of those men and women who have since died have been supplied by the Registrars-General of the U.K. over the ensuing 29 months. This preliminary report is confined to the deaths among the 24,389 men over the age of 35 .

Though the numbers of deaths at present available are small the resulting rates reveal a significant and steadily rising mortality from deaths due to cancer of the lung as the amount of tobacco smoked increases. There is also a rise in the mortality from deaths attributed to coronary thrombosis as the amount smoked increases, but the gradient is much less steep than that revealed by cancer of the lung. The other groups of deaths so far analysed reveal no gradient (other forms of cancer, other forms of cardiovascular disease, respiratory diseases, all other causes).

The figures for cancer of the lung are in conformity with those found previously in an extensive inquiry into the smoking histories of patients with cancer of the lung and with other diseases.

The death rates of doctors here reported are, almost certainly, artificially low. There is evidence that this is due to a reluctance, or inability, of persons suffering from a fatal illness to reply to the questionary. In spite of this defect and the present small numbers of deaths, we thought it necessary, in view of the nature of the results, to lay these preliminary observations before the survivors of the 40,000 men and women who made them possible.

We are most grateful to the British Medical Association for having dispatched the questionaries and letters to the doctors on our behalf: to the individual doctors for having completed the questionaries; and to those practitioners and consultants to whom we wrote for details of the evidence on which the diagnosis of lung cancer was made. We are deeply indebted to the Registrars-General of the United Kingdom for information about the deaths of doctors. We also offer our thanks to Dr. P. Armitage, who suggested the use of Yates's method of assessing the significance of a trend, and to Mrs. Joan Bodington, Miss Muriel Greening, and Miss Keena Jones for the onerous work of filing, coding, and enumerating the questionaries.

\section{REFERENCES}

Breslow, L., Hoaglin, Le M., Rasmussen, G., and Abrams, H. R. (1954) Amer. 'J. publs Hlth, 44,'171. Doll, R., and Hill, A. B. (1950). British Medical, Journat, 2, 739

Koulumies, M. (1953)., Acta radiol, Stockh. 39, 255.

Levin, M. L., Goldstein, H., and Gerhardt, P. R. (1950). J. Amer. med. Ass., 143, 336.

McConnell, $\mathrm{B}$. Gordon $\mathrm{K}$ C. T. and Jones, $T$ (1952) Lancet, 651 Mills, C. A., and Porter, M. M. (1950). Cancer Res., 10, Lance Sadowsky, D. A., Gilliam, A. G., and Cornfield, J. (1953). J. nat Camcer Inst., 13, 1237.

chrek, R., Baker, L. A., Ballard, G. P., and Dolgoff, S. (1950) Cancer Res., 10, 49 .

Watson, W. L., and Conte, A. J. (1954). Cancer, 7, 245 .

Wynder, E. L., and Conficld, J. (1953). New Engl. J. Med., 248, 441 Yates, F. Graham, E. A. (1950). J., Amer. med. Ass., 143, 329.

\title{
Commentary: scientific articles have hardly changed in 50 years
}

\author{
Richard Smith
}

The simultaneous publication of a scientific study from 50 years ago and its current update provides an opportunity for observing changes in presentation. The over-riding impression is of little change. In the 50 years during which men have landed on the moon, computers and the internet have appeared, television and cars have been transformed, the scientific article has changed hardly at all. Does this reflect the robustness of the form or a failure of imagination? I suspect the latter.

The 1954 article was shorter, had fewer references, slightly fewer statistical tests, more basic descriptive data, and crudely drawn figures, but the 2004 article is unusually long and resists the current temptation of statistical overkill.

Both articles have something close to the traditional IMRaD (introduction, methods, results, and discussion) structure, but the 1954 article is more casual in mixing comments that strictly ought to be in the discussion of the results. Both papers are clearly written, but the older paper seems easier to read. In part this might be because it uses the active voice and contains slightly less jargon. The word "prospective" appears in the older paper, perhaps for the first time, and is accompanied by the largely unhelpful quote from Leigh Hunt that "He was a retrospective rather than a prospective man.” The old word for questionnaire-questionary-surprises.

The biggest changes are in what might be called the furniture of the article. The older article has no structured abstract and no contributor, guarantor, and competing interest statements. The 2004 article includes our "what this study adds" box, one of our most popular innovations. Both papers include extensive thanks, but only the older paper gives the degrees and honours of the authors. The older paper says nothing about ethics committee approval, but the new paper tells us that there were no ethics committees in 1951. Some, I know, pine for such a time.

Competing interests: RS is editor of the BMJ and accountable for all it contains.

1 Doll R, Peto R, Boreham J, Sutherland I. Mortality in relation to smoking: 50 years' observations on male British doctors. BMJ 2004:328:1519-33.

Richard Smith editor rsmith@bmj.com 